\title{
Puesta en marcha del Repositorio Institucional de la Universidad Católica de Valencia San Vicente Mártir (RIUCV). Primeros pasos e incertidumbres
}

\author{
Patricia Pérez Velázquez, Jorge Martorell Albert, José López Ortí | Servicio de Biblioteca, Universidad Católica de Valencia San \\ Vicente Mártir
}

URL de la contribución <www.iaph.es/revistaph/index.php/revistaph/article/view/4656>

Los repositorios se han convertido en herramientas clave para la sociedad académica y científica. Se sabe que han experimentado un crecimiento acelerado, no solo en el número de repositorios sino también en el número de publicaciones que contienen. Varios estudios han demostrado la eficacia en la transmisión de los conocimientos científicos. En estos tiempos que corren, donde el acceso abierto a la información proporciona más ventajas que inconvenientes, ninguna comunidad universitaria se plantea la vida sin esta herramienta. Y nosotros no íbamos a ser menos, de ahí la creación y puesta en marcha de RIUCV (Repositorio Institucional de la Universidad Católica de Valencia San Vicente Mártir).

RIUCV se ha estado gestando desde principios del año 2016, pero no fue hasta el verano de 2019 cuando por fin vio la luz. Sabíamos que la producción y creación de esta herramienta no iba a resultar fácil, ya que el Servicio de Biblioteca de la UCV no disponía de la tota-

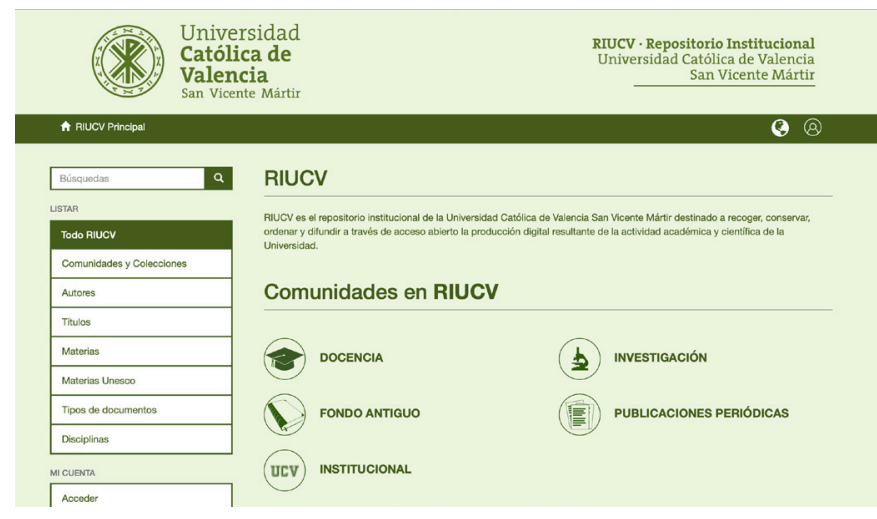

RIUCV (Repositorio Institucional de la Universidad Católica de Valencia San Vicente Mártir) lidad de los medios necesarios para hacerle frente, pero tampoco imaginábamos que iba a ser tan complicado en ciertos aspectos.

La mayoría de las universidades deben apoyarse en empresas externas para que el repositorio institucional se convierta en realidad. Cuando un servicio se externaliza supone la aparición de ciertos inconvenientes, ya que la herramienta es nuestra pero el control se acaba perdiendo, principalmente cuando nos disponemos a cambiar o modificar contenidos, como es el caso de:

> La estructura (comunidades y colecciones, banners, títulos, enlaces...).

$>$ El diseño de la interfaz (colores, disposición de las imágenes y/o símbolos, tipo de letra, alineación del texto, iconos...).

> Incorporación de documentos, guías y/o políticas.

Muchas de las ideas que se tenían en principio en mente desaparecieron o se modificaron; al final la empresa externa es la que tiene la última palabra. Por tanto, ¿es más rentable que la propia universidad sea capaz de gestionar el repositorio en su totalidad? Hay que reconocer que contar con los servicios de esas empresas es de gran ayuda también, sobre todo en la resolución de problemas y/o errores, ya que la comunicación entre ambas organizaciones suele ser rápida y fluida.

Actualmente, RIUCV se encuentra en una etapa intermedia de desarrollo. Gracias a la presentación oficial del repositorio a la comunidad universitaria, se ha comenzado a realizar la inclusión de la producción científica de los autores. En este punto, surgen otras cuestiones 
que dan valor añadido a la figura del bibliotecario. Nos damos cuenta del desconocimiento de la herramienta en sí y nos preguntamos si la universidad, como institución, es conocedora de las posibilidades, funcionalidades y repercusión que supone un sistema de esta índole. ¿Y los autores? Muchos de ellos anteponen la publicación de su producción científica en el repositorio a la publicación en otras plataformas como ResearchGate y Academia.edu. En nuestro caso, hemos tenido que lidiar con comentarios del profesorado del tipo "Yo tengo mi producción científica publicada en Academia.edu y no tengo intención de que aparezca en ningún otro sitio" o "No me parece mala idea la creación y puesta en marcha de RIUCV, pero yo estoy contento/a con Academia.edu donde tengo depositada toda mi producción científica". Dado el tema de este debate, ¿cuál es el lugar correcto para depositar esos documentos?, ¿existe cierta contrariedad en la duplicidad de la producción científica en varios medios? A pesar de todas las trabas encontradas en este entorno, cabe destacar la gran acogida, en general, que ha tenido RIUCV en nuestra comunidad universitaria.

Otro aspecto relevante es la formación del personal al frente del servicio. Además del nuevo reto que supone la creación de la herramienta, se le debe añadir la responsabilidad que adquiere la biblioteca. Entran en juego cuestiones relacionadas con temas legislativos, de propiedad intelectual, derechos de autor, políticas, etc. ¿Hasta qué punto deben estar los profesionales de la biblioteconomía y la documentación preparados para ello? ¿Existen cursos de formación a la altura, que nos aseguren ser, totalmente, autónomos para resolver dichas cuestiones? ¿Es competencia de la universidad que sus profesionales al frente del repositorio estén bien formados o depende del propio personal de la biblioteca?

En definitiva, somos conscientes de que hace falta formación por y para los usuarios de los repositorios institucionales, pero no se debe descuidar la formación por y para los profesionales de la información que son los que están al frente del servicio. Otra cuestión, que es interesante plantear, es la formación por y para los estudian-

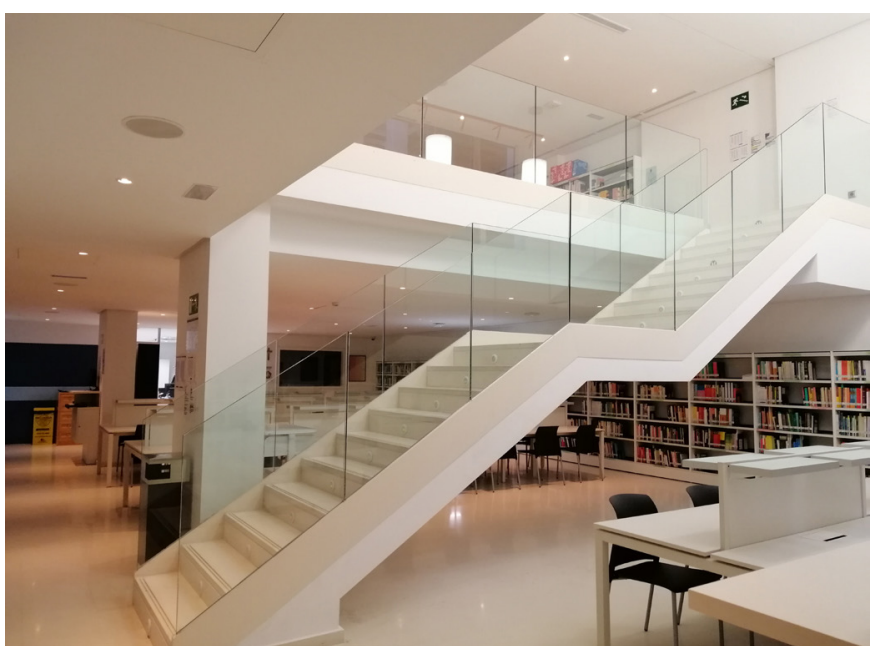

Biblioteca de la Facultad de Magisterio y Ciencias de la Educación de la Universidad Católica de Valencia San Vicente Mártir

tes, no solo para el personal docente e investigador. Las universidades son instituciones que tienen disparidad de perfiles de usuarios por lo que sería lógico plantearse programas de formación a medida y no tan genéricos como ocurre en la mayoría de los casos.

Para finalizar, conviene mencionar la ayuda que nos han brindado los compañeros y colegas de la profesión a lo largo de todo este tiempo. En los momentos en los que teníamos dudas o no sabíamos a quién acudir y nos sentíamos perdidos, hemos contactado a través de correo-e. y telefónicamente con personal de distintas universidades españolas al frente de repositorios. Los profesionales de la información destacamos, entre otras cosas, por nuestro carácter y espíritu colaborativo y, esta vez, no iba a ser menos. Todos esos ánimos y apoyos proporcionados permiten sumergirnos en nuevas iniciativas y, lo más importante, sacarlas adelante. 